\title{
Insulin resistance in skeletal muscle of the male Otsuka Long-Evans Tokushima Fatty rat, a new model of NIDDM
}

\author{
T. Sato, Y.Asahi, K. Toide, N. Nakayama \\ Tokushima Research Institute, Otsuka Pharmaceutical Co., Ltd., Tokushima, Japan
}

\begin{abstract}
Summary The Otsuka Long-Evans Tokushima Fatty rat is a new inbred obese strain with a late onset and chronic course of spontaneous hyperglycaemia in the male, and is considered to be a model of non-insulindependent diabetes mellitus $[1,2]$. Fat distribution analysis showed a typical accumulation of intra-abdominal visceral fat in Otsuka Long-Evans Tokushima Fatty rats compared with a control strain, Long-Evans Tokushima Otsuka rats. To examine the insulin sensitivity of Otsuka Long-Evans Tokushima Fatty rats, we performed euglycaemic hyperinsulinaemic clamp experiments in vivo in rats under anaesthesia on this strain and on Long-Evans Tokushima Otsuka rats. The Otsuka Long-Evans Tokushima Fatty rats showed lower values for the glucose infusion rate $(60 \%$ of the control at 12 weeks old and $20-30 \%$ of the control at $18,24,30$ and 39 weeks old) than age-matched controls, indicating the development of insulin resistance with age. Hindlimb perfusion experiments in vitro also showed a $45 \%$ decrease of insulin-stimulated glucose uptake in Ot-
\end{abstract}

suka Long-Evans Tokushima Fatty rats in the diabetic stage. These results indicate that insulin resistance exists in the skeletal muscle of Otsuka LongEvans Tokushima Fatty rats. To obtain information on the mechanism of insulin resistance in the skeletal muscle of Otsuka Long-Evans Tokushima Fatty rats, the insulin binding, autophosphorylation and tyrosine kinase activity of their partially-purified insulin receptors in vitro were compared with those from control rats. The results showed no marked differences in these insulin receptor functions between diabetic and control rats. These results suggest that it is unlikely that severe insulin-receptor dysfunction is responsible for the insulin resistance in the skeletal muscle of Otsuka Long-Evans Tokushima Fatty rats. [Diabetologia (1995) 38: 1033-1041]

Key words Otsuka Long-Evans Tokushima Fatty rats, intra-abdominal visceral fat, insulin resistance, insulin receptor, skeletal muscle.
The Otsuka Long-Evans Tokushima Fatty (OLETF) rat is a new inbred strain with a late onset, chronic and slow progress of hyperglycaemia in the male [1]. Specifically, OLETF rats show innate polyphagia,

Received: 27 May 1994 and in final revised form: 17 May 1995

Corresponding author: T.Sato, IRST project, Tokushima Research Institute, Otsuka Pharmaceutical Co., Ltd., 463-10, Kagasuno, Kawauchi-Cho, Tokushima 771-01, Japan Abbreviations: OLETF, Otsuka Long-Evans Tokushima Fatty; LETO, Long-Evans Tokushima Otsuka; ECL, enhanced chemiluminescence; $\mathrm{K}_{\mathrm{d}}$, dissociation constant; $\mathbf{B}_{\max }$, maximal binding; BSA, bovine serum albumin. which causes rapid body weight gain resulting in hyperinsulinaemia, hypertriglyceridaemia and hyperglycaemia. The oral glucose tolerance test $(2 \mathrm{~g} / \mathrm{kg}$, orally) shows that diabetes develops at around 1825 weeks old, which is a rather later onset than in other animal non-insulin-dependent diabetes mellitus (NIDDM) models such as the ob/ob mouse, the $\mathrm{db} / \mathrm{db}$ mouse, the KKA ${ }^{y}$ mouse and the Wistar fatty rat. At later than 40 weeks old, an insulin-deficient state and renal complications such as glomerulosclerosis have been observed [2]. The control strain, which never develops diabetes in its entire life, was also established from the same closed colony of Long-Evans rats from Charles River Canada 
(St.Constant, Québec, Canada) and named LongEvans Tokushima Otsuka (LETO) rat. Therefore, it might be useful to study the pathogenetic mechanism(s) of NIDDM in OLETF rats in which the disease has many similarities to that in humans. Recently, visceral obesity, but not gluteo-femoral obesity, has been considered to be related to glucose intolerance and cardiovascular disease [3-5]. However, there is no appropriate obese animal model which shows visceral fat accumulation and glucose intolerance, and the mechanism(s) of insulin resistance has not yet been elucidated.

The initial mechanisms of insulin receptor signal transduction were thought to be as follows: the binding of insulin to its receptor activates the receptor tyrosine kinase, causing autophosphorylation of tyrosine residues of the receptor. The activated insulin receptor tyrosine kinase also phosphorylates intracellular substrates that transduce the insulin signal [6-8] which is eventually expressed as glucose uptake, glycogen synthase activation and many other events. Receptor autophosphorylation and the activation of its tyrosine kinase are considered to be essential for insulin signal cascades [9-11], and several studies have suggested that insulin receptor tyrosine kinase activity is reduced in NIDDM patients [12-15].

In this study, the obesity of OLETF rats was characterized by weighing intra-abdominal visceral fat and by blood biochemistry. The development of insulin resistance was then examined in vivo by a euglycaemic hyperinsulinaemic clamp technique. In addition, the existence of insulin resistance in the skeletal muscle was confirmed using hindlimb perfusion, and insulin receptor functions such as insulin binding, autophosphorylation, and tyrosine kinase activity, were examined in vitro. Finally, the relationship between the accumulation of intra-abdominal visceral fat and insulin sensitivity in OLETF rats was examined.

\section{Materials and methods}

Materials. Porcine insulin, bovine serum albumin (BSA, fraction V), human gamma-globulin, Poly Glu-Tyr (4:1), bacitracin, phenylmethylsulfonyl fluoride, benzamidine, aprotinin and ovalbumin were purchased from Sigma (St.Louis, Mo., USA). Porcine monocomponent insulin was obtained from Novo (Copenhagen, Denmark). Wheat germ agglutinin-Sepharose $6 \mathrm{MB}$ and dextran T70 were obtained from Pharmacia (Uppsala, Sweden). Polyethylene glycol 6000 was obtained from Nacalai Tesque (Osaka, Japan). ${ }^{125}$ I-labelled insulin was obtained from DuPont-NEN Boston, Mass., USA). An enhanced chemiluminescence (ECL) Western blotting detection system, peroxidase-labelled anti-mouse or anti-rabbit immunoglobulin antibodies and autoradiography film (HyperfilmECL) were obtained from Amersham International (Amersham, Bucks., UK). Mouse anti-phosphotyrosine antibody (PY 20) was obtained from ICN Biomedicals (Costa Mesa, Calif., USA). Rabbit anti-rat insulin receptor $\beta$ subunit antibody was kindly provided by Dr. T.Kadowaki of the University of Tokyo (Tokyo, Japan). Other chemicals were purchased from
Wako Pure Chemicals (Osaka, Japan). LETO and OLETF rats were raised at the Tokushima Research Institute (Otsuka Pharmaceutical Co., Ltd., Tokushima, Japan).

Body fat analysis. Rats $(6,12,18,24$ and 30 weeks old of both LETO and OLETF strains) were anaesthetized with pentobarbital $(50 \mathrm{mg} / \mathrm{kg}$, i.p.) and inserted into a small-animal body composition analyser (EM-SCAN model SA-2, EM-SCAN Inc., Springfield, Ill., USA) to estimate total body fat content. Retroperitoneal, epididymal and mesenteric fats were removed and weighed after blood sampling during dissection. The residual fats, which were assumed to be mainly subcutaneous, were calculated by subtracting the visceral fat weight (sum of retroperitoneal, epididymal and mesenteric fats) from the total body fat content.

Oral glucose tolerance test and euglycaemic clamp. All animals $(6,12,18,24,30$ and 39 -week-old rats) were subjected to an oral glucose tolerance test for the diagnosis of diabetes 1 week before the glucose clamp experiment. Briefly, blood glucose was measured using a glucose analyser (ANTSENSE, Miles-Sankyo, Tokyo, Japan) by a glucose electrode method after administration of $2 \mathrm{~g} / \mathrm{kg}$ of oral glucose (pre, 30, 60, 90 and $120 \mathrm{~min}$ ). Rats were classified into three types based on the results of the oral glucose tolerance test: 1) those showing a peak blood glucose level of more than $16.8 \mathrm{mmol} / \mathrm{l}$ and a blood glucose level of more than $11.2 \mathrm{mmol} / \mathrm{l}$ at $120 \mathrm{~min}$ were diagnosed as diabetic; 2) those showing only one of the above two criteria were classified as impaired glucose tolerance, and 3) those showing neither diabetes nor impaired glucose tolerance were classified as normal. Male OLETF rats and age-matched LETO rats were used in all experiments. After fasting overnight, the animals were anaesthetized with pentobarbital $(50 \mathrm{mg} / \mathrm{kg}$, i.p.), and polyethylene catheters (PE-60, Becton Dickinson and Co., Parsippany, N.J., USA) were inserted into the jugular and femoral veins. Porcine monocomponent insulin in $0.9 \% \mathrm{NaCl}$ with $0.25 \% \mathrm{BSA}$ was then infused into the femoral vein at $10 \mathrm{mU} \cdot \mathrm{min}^{-1} \cdot \mathrm{kg}^{-1}$. Bolus doses of insulin were infused at rates of 30,20 and $14 \mathrm{mU} \cdot \mathrm{min}^{-1} \cdot \mathrm{kg}^{-1}$ at $0 \sim 3,3 \sim 6$, and $6-10 \mathrm{~min}$, respectively, after the start of the experiment. Blood samples were taken from the jugular vein every 2 or $4 \mathrm{~min}$, blood glucose was monitored by ANTSENSE, and the glucose was infused at the rate calculated for the infusion of $10 \%$ glucose to maintain a blood glucose level of $6.1 \mathrm{mmol} / 1$. The total body glucose infusion rate $\left(\mathrm{mg} \cdot \mathrm{min}^{-1} \cdot \mathrm{kg}^{-1}\right)$ was assessed as the mean value from 40 to $60 \mathrm{~min}$.

Hindlimb perfusion experiments. The animals (40 weeks old), which were different from those for the body fat analysis or glucose clamp experiments, were fasted for two nights as described by Ruderman et al. [16], and then anaesthetized with pentobarbital $(50 \mathrm{mg} / \mathrm{kg}$, i. p.). The right hindlimb was perfused with Krebs-Ringer bicarbonate buffer containing $7.2 \mathrm{mmol} / 1$ glucose, $3.5 \%$ dextran $\mathrm{T} 70$ and $0.5 \% \mathrm{BSA}$ at a flow rate of $10 \mathrm{ml} / \mathrm{min}$ in a non-circulating manner through an abdominal aorta cannula. Only the right femoral artery was perfused, and other branches of arteries were ligated to prevent the perfusion of tissues other than the right hindlimb skeletal muscle. After a period of equilibrium, porcine insulin was infused at $1 \mathrm{mU} / \mathrm{ml}$ and the glucose concentration of the perfusate from the right femoral vein was monitored using a 2700 Biochemistry Analyzer (YSI Inc., Yellow Springs, Ohio, USA). The weight of the hindlimb skeletal muscle was calculated as $5 \%$ of the lean body mass based on the results of preliminary experiments. The lean body mass was measured by EM-SCAN as mentioned above. 
Partial purification of insulin receptors. Insulin receptors were solubilized by homogenizing the hindlimb skeletal muscle from animals at 28 weeks old with $25 \mathrm{mmol} / \mathrm{l} \mathrm{Hepes,} 1 \%$ Triton X-100, $4 \mathrm{mmol} / \mathrm{l}$ EDTA, 1 trypsin inhibitor U/ml aprotinin, and $2 \mathrm{mmol} / \mathrm{l}$ phenylmethylsulfonyl fluoride $(\mathrm{pH} 7.4)$ and then partially purified using a wheat germ agglutinin-Sepharose column as described by Burant et al. [17], and this fraction was used for the insulin binding experiments. Because this partially purified insulin receptor fraction was consumed in the insulin binding experiments, animals at 30 weeks old were used for the determination of receptor autophosphorylation and receptor tyrosine kinase activity. These 28- and 30week-old OLETF rats were all judged to be diabetic from oral glucose tolerance tests, and they were considered to have the same basic characteristics. For the receptor autophosphorylation and tyrosine kinase study, protein tyrosine phosphatase inhibitors and protease inhibitors were added to homogenization buffer $(10 \mathrm{v} / \mathrm{g}$ tissue, containing $50 \mathrm{mmol} / 1 \mathrm{Hepes}, 2 \%$ Triton $\mathrm{X}-100,4 \mathrm{mmol} / 1$ orthovanadate, $10 \mathrm{mg} / \mathrm{ml}$ bacitracin, $4.5 \mathrm{mmol} / \mathrm{l}$ phenylmethylsulfonyl fluoride, $10 \mathrm{mmol} / \mathrm{l}$ benzamidine, 300 kallikrein inhibitor units $/ \mathrm{ml}$ aprotinin, $20 \mathrm{mmol} / \mathrm{l}$ EDTA, $20 \mathrm{mmol} / 1$ sodium pyrophosphate, $150 \mathrm{mmol} / \mathrm{l} \mathrm{NaF}$, and $2 \mathrm{mmol} / \mathrm{l}$ dichloroacetic acid, $\mathrm{pH}$ 7.4) as described by Freidenberg et al. [18]. The protein concentration was assayed by the method described by Bradford using gamma-globulin standards [19].

Insulin binding experiments. The eluate from wheat germ agglutinin ( $50 \mu \mathrm{l}$ of eluate, up to $17 \mu \mathrm{g}$ of glycoprotein) was incubated with ${ }^{125}$ I-labelled and unlabelled insulin $\left(0 \sim 3 \times 10^{-}\right.$ ${ }^{7} \mathrm{~mol} / \mathrm{l}$ ) in buffer containing $25 \mathrm{mmol} / \mathrm{l}$ Hepes $(\mathrm{pH} 7.4), 0.1 \%$ Triton X-100, $150 \mathrm{mmol} / \mathrm{l} \mathrm{NaCl}$, and $0.1 \%$ BSA for $18 \mathrm{~h}$ at $4{ }^{\circ} \mathrm{C}$. The ligand-receptor complex was precipitated with $25 \%$ polyethylene glycol 6000 and $0.3 \%$ human gamma-globulin, washed with $12.5 \%$ polyethylene glycol 6000 and counted using a slight modification of the method described by Burant et al. [20]. The maximal binding $\left(B_{\max }\right)$ and dissociation constant $\left(\mathrm{K}_{\mathrm{d}}\right)$ were determined using the radioligand binding analysis computer program of McPherson GA (BIOSOFT, Cambridge, UK).

Receptor autophosphorylation. Receptor autophosphorylation was analysed using a slight modification of the method described by Burant et al. [20]. Briefly, the eluate from a wheat germ agglutinin column (up to $25 \mu \mathrm{l}$ of eluate, up to $7 \mu \mathrm{g}$ of glycoprotein) was incubated in buffer containing $50 \mathrm{mmol} / \mathrm{l}$ Hepes $(\mathrm{pH} 7.4), 0.1 \%$ Triton $\mathrm{X}-100,5 \mathrm{mmol} / \mathrm{l} \mathrm{MnCl}_{2}$, and $0.05 \% \mathrm{BSA}$ with various concentrations of porcine insulin $\left(0 \sim 10^{-8} \mathrm{~mol} / \mathrm{l}\right)$ for $45 \mathrm{~min}$ at $25^{\circ} \mathrm{C}$. After the addition of ATP $(100 \mu \mathrm{mol} / \mathrm{l}$ in final concentration) the mixtures were incubated for $30 \mathrm{~min}$ at $4^{\circ} \mathrm{C}$. The reaction was stopped by adding loading buffer and boiling for $3 \mathrm{~min}$, and then the mixtures were electroblotted to polyvinylidene difluoride membrane (Bio-Rad Laboratories, Hercules, Calif., USA). The membrane was treated with mouse anti-phosphotyrosine antibody $(\alpha \mathrm{PY})(1: 1000)$ followed by a second peroxidase-labelled antibody treatment (1:1000). Autophosphorylation was detected using a non-radioisotopic ECL method as a fluorogram on autoradiography film, and the density of the band at the insulin receptor $\beta$ subunit position was measured using an ULTROSCAN XL, Enhanced Laser Densitometer (LKB, Bromma, Sweden). The amount of insulin receptor in the wheat germ agglutinin column fraction was estimated by Western blotting with rabbit anti-rat insulin receptor $\beta$ subunit antibody (1:500) using an ECL method followed by densitometry and normalized. To normalize the intensity of the fluorograms of each Western blot experiment, a known amount of phosphotyro- sylated ovalbumin was applied on the SDS-PAGE along with samples, and the densitometric values of phosphotyrosylated ovalbumin position of the fluorograms were used after Western blotting. The phosphotyrosylated ovalbumin was synthesized by coupling reaction with 1-ethyl-3-(3-dimethyl aminopropyl) carbodiimide of phosphotyrosine and ovalbumin, and phosphotyrosine residues per molar of ovalbumin were determined by competitive ELISA using anti-phosphotyrosine antibody and free phosphotyrosine.

Insulin receptor tyrosine kinase activity. Insulin receptor tyrosine kinase activity was determined by a slight modification of the method of Rijksen et al. [21]. Insulin receptors normalized as above (up to $25 \mu \mathrm{l}$ of eluate, up to $7 \mu \mathrm{g}$ of glycoprotein) were diluted 10 fold and incubated with various concentrations of insulin $\left(0 \sim 10^{-7} \mathrm{~mol} / \mathrm{l}\right)$ in $50 \mathrm{mmol} / \mathrm{l}$ Hepes $(\mathrm{pH} 7.4)$ containing $0.1 \%$ Triton $\mathrm{X}-100$ and $10 \mathrm{mmol} / \mathrm{MgCl}_{2}$ for $60 \mathrm{~min}$ at room temperature. ATP $(50 \mu \mathrm{mol} / 1$ in final concentration) and Poly Glu-Tyr (4:1, $2 \mathrm{mg} / \mathrm{ml}$ in final concentration) were added, and the mixture was incubated for $10 \mathrm{~min}$ at room temperature. In vitro receptor tyrosine kinase activity was detected as tyrosine phosphorylation of Poly Glu-Tyr (4:1) using an ECL method after slot-blotting onto a polyvinylidene difluoride membrane as described above.

Blood analysis. Fasting blood glucose was measured by ANTSENSE. Serum triglyceride and cholesterol were analysed using commercial kits (Wako Pure Chemicals, Osaka, Japan). Serum insulin was determined by radioimmunoassay (Amersham).

\section{Statistical analysis}

All values are expressed as the mean \pm SEM. Statistical significances in values for body weight, fat weight, fasting blood glucose, serum triglyceride, serum cholesterol, serum insulin, and glucose infusion rate were examined by two-way analysis of variance (ANOVA) followed by the $t$-test. Data obtained in the hindlimb perfusion experiments were examined by the $t$-test. The experiment on receptor autophosphorylation was analysed by ANOVA (repeated measurements.) $p$ values of less than 0.05 were considered to be significant.

\section{Results}

Body fat analysis. To study the characteristics of obesity of OLETF rats, body fat analysis and blood biochemistry were carried out in rats which were different from those used for the glucose clamp studies, but of the same ages, with the exception of those at 39 weeks old. The comparisons of intra-abdominal visceral (retroperitoneal, epididymal and mesenteric) fat and total fat after intra-abdominal visceral fat subtraction (mainly subcutaneous fat) of LETO and OLETF rats $(6,12,18,24$, and 30 weeks old) are shown in Figure 1.

The sharp accumulation of intra-abdominal visceral fat, especially retroperitoneal fat, was evident in OLETF rats from 12 weeks old (Fig. $1 \mathrm{~A}$ ). Retroperitoneal and mesenteric fat mass of OLETF rats were significantly greater in OLETF rats than in 
A

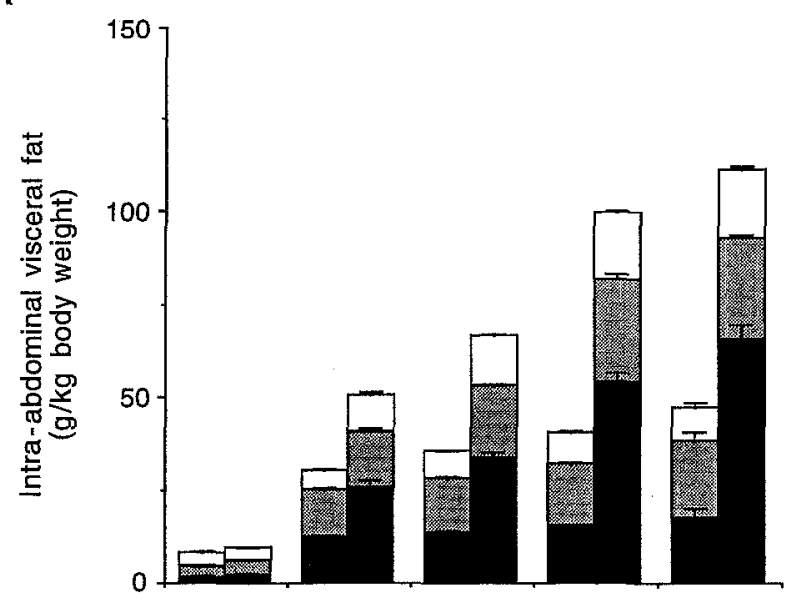

B

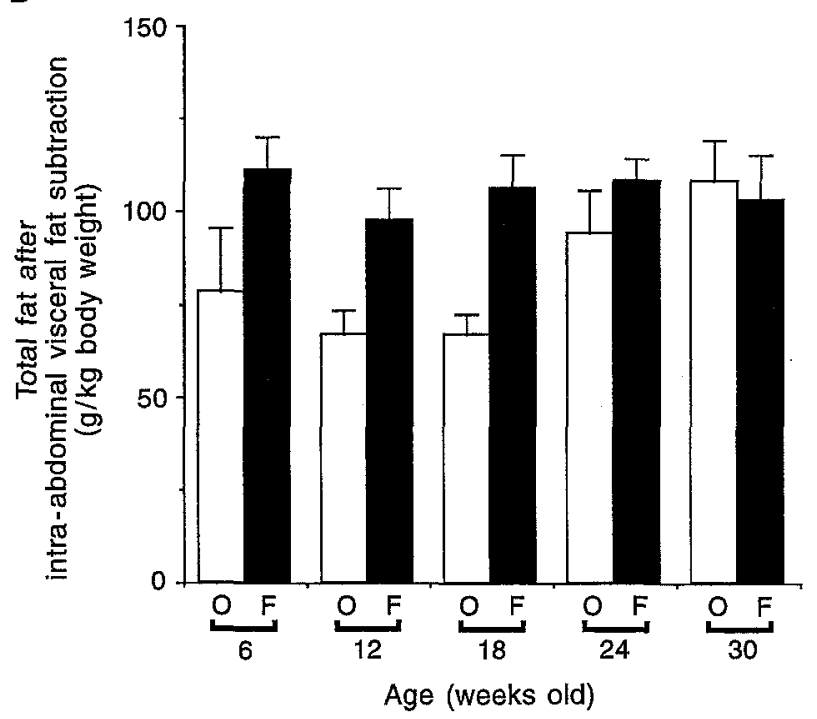

Fig.1 (A, B). Comparison of fat weight $/ \mathrm{kg}$ body weight of LETO and OLETF rats. A Intra-abdominal visceral fat, in-

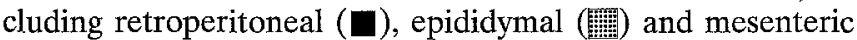
( $\square$ ) fat weights in 6-, 12-, 18-, 24- and 30-week-old LETO and OLETF rats. B Total fat after intra-abdominal visceral fat subtraction (basically considered to be subcutaneous fat) weights calculated by subtracting retroperitoneal, epididymal and mesenteric fat weights from total body fat weights determined by analysis using a small-animal body composition analyser (EM-SCAN model SA-2), in 6-, 12-, 18-, 24- and 30-weekold LETO and OLETF rats; O: LETO, F: OLETF rats. Mean $\pm \operatorname{SEM}(n=5)$

LETO rats from 18 weeks old ( $p<0.001)$, whereas residual fat was not (Fig. 1B). The body weight, fasting blood glucose, serum triglyceride, serum cholesterol and serum insulin of the LETO and OLETF rats used for this body fat analysis are shown in Table 1 .

Body weights of OLETF rats were significantly higher than those of LETO rats from 6 weeks old. Fasting blood glucose was higher in OLETF rats than in LETO rats from 6 weeks old and the difference was significant at 18 and 30 weeks old. Serum triglyceride of OLETF rats increased from 2.3- to 4.1-fold from 12 weeks old. Higher serum cholesterol was observed in OLETF rats than in LETO rats at 12,24, and 30 weeks old. Fasting serum insulin was higher in OLETF rats, but it was significant only at 6 weeks old due to individual variance.

Oral glucose tolerance test and euglycaemic clamp. One week before the clamp experiments, all rats were subjected to an oral glucose tolerance test. None of the OLETF or LETO rats had diabetes at 5 weeks old. Three of ten OLETF rats had impaired glucose tolerance at 11 weeks old, and all the OLETF rats were diagnosed as having diabetes at 17, 23, 29 and 38 weeks old. The body weights and fasting blood glucose levels of the rats used in the clamp experiments are shown in Table 2. The body weights of OLETF rats were significantly higher than those of LETO rats from 12 weeks old. The fasting blood glucose of OLETF rats also increased significantly from 18 weeks old.

To investigate insulin resistance in OLETF rats at various ages, glucose clamp experiments were carried out under euglycaemic and hyperinsulinaemic conditions. Figure 2 shows the results of the clamp experiment for 30-week-old rats. After insulin infusion $\left(10 \mathrm{mU} \cdot \mathrm{min}^{-1} \cdot \mathrm{kg}^{-1}\right)$ the blood glucose level slowly decreased within $40 \mathrm{~min}$ and clamped around $6.1 \mathrm{mmol} / \mathrm{l}$ in both cases (Fig. $2 \mathrm{~A}$ ). On the other hand, the glucose infusion rate of OLETF rats was significantly lower than that of LETO rats, indicating the existence of insulin resistance (Fig. 2B). Although, there was no significant decrease in the glucose infusion rate at 6 weeks old, the glucose infusion rate of 12-week-old OLETF rats was significantly reduced (approximately $60 \%$ of that of the control). The glucose infusion rates of OLETF rats were also lower than those of control rats (about $25 \%$ of that of the control) in older rats $(18,24$ and 39 weeks old) (Fig. 3). Although there were deviations in the glucose infusion rates of various ages of LETO rats, they were not statistically significant. Serum insulin levels of OLETF rats after the clamp experiments at 30 weeks old were slightly higher than those of LETO rats, but this difference was not significant $(284 \pm 27$ and $440 \pm 69 \mathrm{mU} / \mathrm{l}$ in LETO and OLETF rats, respectively). These results suggest that the insulin resistance of OLETF rats appeared at 12 weeks old and became more severe from 18 weeks old.

Hindlimb perfusion. Skeletal muscle is considered to be the major tissue for peripheral glucose uptake. To confirm whether or not the decreased glucose infusion rate was due to decreased insulin-stimulated glucose uptake in skeletal muscle, we performed hindlimb perfusion on OLETF rats in the diabetic stage (40 weeks old) and in age-matched control rats. The basal glucose uptake reached a plateau within 
Table 1. Characteristics of the Long-Evans Tokushima Otsuka and Otsuka Long-Evans Tokushima Fatty rats used for body fat analysis

\begin{tabular}{|c|c|c|c|c|c|}
\hline $\mathrm{Ag}$ (weeks) & Body weight $(\mathrm{g})$ & $\begin{array}{l}\text { Fasting blood } \\
\text { glucose }(\mathrm{mmol} / \mathrm{l})\end{array}$ & $\begin{array}{l}\text { Serum triglyceride } \\
(\mathrm{mmol} / \mathrm{l})\end{array}$ & $\begin{array}{l}\text { Serum cholesterol } \\
(\mathrm{mmol} / \mathrm{l})\end{array}$ & Serum insulin $(\mathrm{mU} / \mathrm{l})$ \\
\hline LETO & $115 \pm 5$ & $3.94 \pm 0.24$ & $0.901 \pm 0.086$ & $3.03 \pm 0.08$ & $26.4 \pm 3.4$ \\
\hline 6 OLETF & $137 \pm 5^{a}$ & $4.57 \pm 0.43$ & $0.763 \pm 0.132$ & $2.72 \pm 0.08^{\mathrm{a}}$ & $46.8 \pm 3.8^{b}$ \\
\hline 12 OLETF & $424 \pm 18^{a}$ & $5.19 \pm 0.38$ & $0.995 \pm 0.115^{\mathrm{b}}$ & $2.47 \pm 0.04^{b}$ & $98.6 \pm 22.8$ \\
\hline [ LETO & $407 \pm 10$ & $5.34 \pm 0.17$ & $0.483 \pm 0.026$ & $2.42 \pm 0.09$ & $79.0 \pm 13.4$ \\
\hline 18 L OLETF & $495 \pm 11^{\mathrm{c}}$ & $6.28 \pm 0.28^{\mathrm{a}}$ & $1.13 \pm 0.07^{\mathrm{c}}$ & $2.61 \pm 0.08$ & $106 \pm 20$ \\
\hline [ LETO & $479 \pm 18$ & $5.32 \pm 0.14$ & $0.584 \pm 0.058$ & $2.54 \pm 0.08$ & $123 \pm 27$ \\
\hline 30 L OLETF & $631 \pm 8^{\mathrm{c}}$ & $7.56 \pm 0.33^{\mathrm{c}}$ & $2.42 \pm 0.12^{\mathrm{c}}$ & $3.39 \pm 0.18^{b}$ & $152 \pm 24$ \\
\hline
\end{tabular}

Mean \pm SEM. ${ }^{\mathrm{a}} p<0.05 ;{ }^{\mathrm{b}} p<0.01 ;{ }^{\mathrm{c}} p<0.001$ vs age-matched LETO rats

Table 2. Body weight and fasting blood glucose of the Long-Evans Tokushima Otsuka and Otsuka Long-Evans Tokushima Fatty rats used for glucose clamp experiments

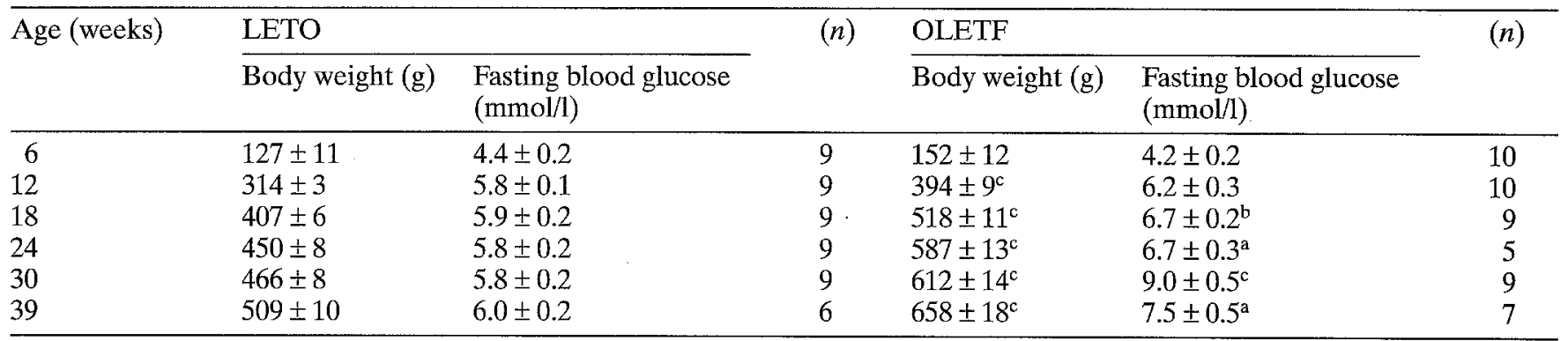

Mean \pm SEM. ${ }^{\mathrm{a}} p<0.05 ;{ }^{\mathrm{b}} p<0.01 ;^{\mathrm{c}} p<0.001$ vs age-matched LETO rats

$40 \mathrm{~min}$ (Fig. 4 A). Insulin infusion $(1 \mathrm{mU} / \mathrm{ml})$ then stimulated a rapid decrease of the glucose concentration in the perfusate, and once again reached a plateau. This insulin-stimulated glucose uptake, calculated as the difference in the glucose concentration of the plateau states before and after insulin infusion, was decreased in OLETF rats in the diabetic stage to $55 \%$ of that of LETO rats (231.6 $22.3 \mathrm{nmol} \cdot \mathrm{min}^{-1} \cdot \mathrm{g}^{-1}$ lean body mass in OLETF rats and $437.8 \pm 24.0$ in LETO rats, $p<0.001$ ), suggesting the existence of insulin resistance in the skeletal muscle itself (Fig.4B).

Analysis of insulin receptor functions. To elucidate the mechanism of insulin resistance in the skeletal muscle of OLETF rats, we partially purified insulin receptors from the skeletal muscle of 30-week-old OLETF and LETO rats and examined their insulin binding activity ( $n=3$, two experiments, Fig. 5). Scatchard analysis with one site model showed no marked differences between the two groups in $B_{\max }$ $(1.72 \pm 0.09$ and $1.66 \pm 0.03 \mathrm{pmol} / \mathrm{mg}$ protein in LETO and OLETF rats, respectively) or $\mathrm{K}_{\mathrm{d}}$ $(1.91 \pm 0.18$ and $1.83 \pm 0.34 \mathrm{nmol} / 1$ in LETO and OLETF rats, respectively) after normalization with glycoprotein.

Autophosphorylation of the insulin receptor in the wheat germ agglutinin-eluate fractions was ex- amined in vitro as described in Materials and methods ( $n=5$, Fig. 6 A). Autophosphorylation increased concomitantly with the exogenous insulin concentration. As shown in Figure 6B, there were no significant differences in insulin-stimulated receptor autophosphorylation between control and OLETF rats after standardization with rabbit anti-rat insulin receptor $\beta$ subunit antibody. Basal densitometric values of the autophosphorylation were $0.0131 \pm 0.0038$ and $0.128 \pm 0.056$ in LETO and OLETF rats, respectively.

Receptor tyrosine kinase activity was also investigated by slot-blotting with anti-phosphotyrosine antibody detected by ECL. The exogenous substrates (Poly Glu-Tyr (4:1)) were phosphorylated in an insulin concentration-dependent manner (Fig. 7 A). However, the insulin-stimulated tyrosine kinase activity at each insulin concentration was not markedly different between OLETF and control rats (Fig. 7B). Basal densitometric values of the activity were $0.409 \pm 0.019$ and $0.497 \pm 0.054$ in LETO and OLETF rats, respectively.

These results indicated that there were no statistically significant abnormalities in insulin-stimulated receptor autophosphorylation, and no marked decreases in $\mathrm{K}_{\mathrm{d}}$ or $\mathrm{B}_{\max }$ of insulin binding or in the tyrosine kinase activity of the insulin receptor in the skeletal muscle of OLETF rats in vitro compared to 
A

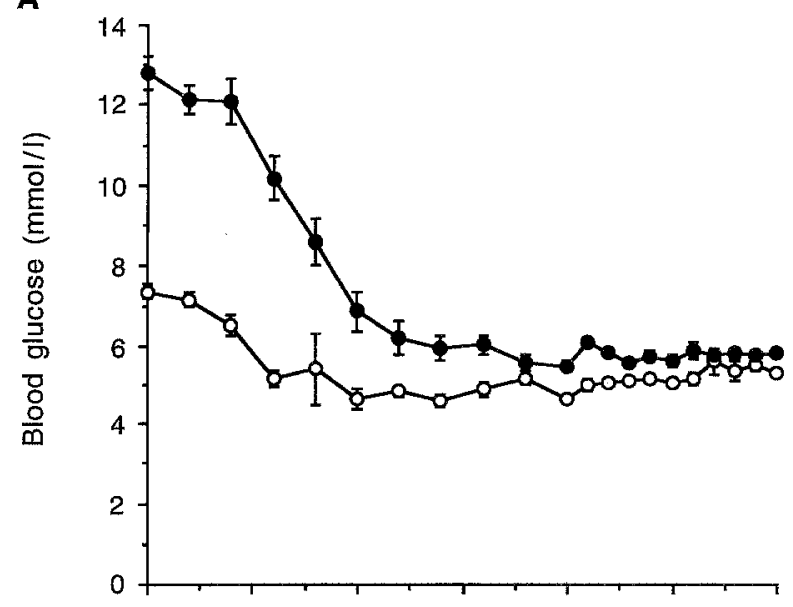

B

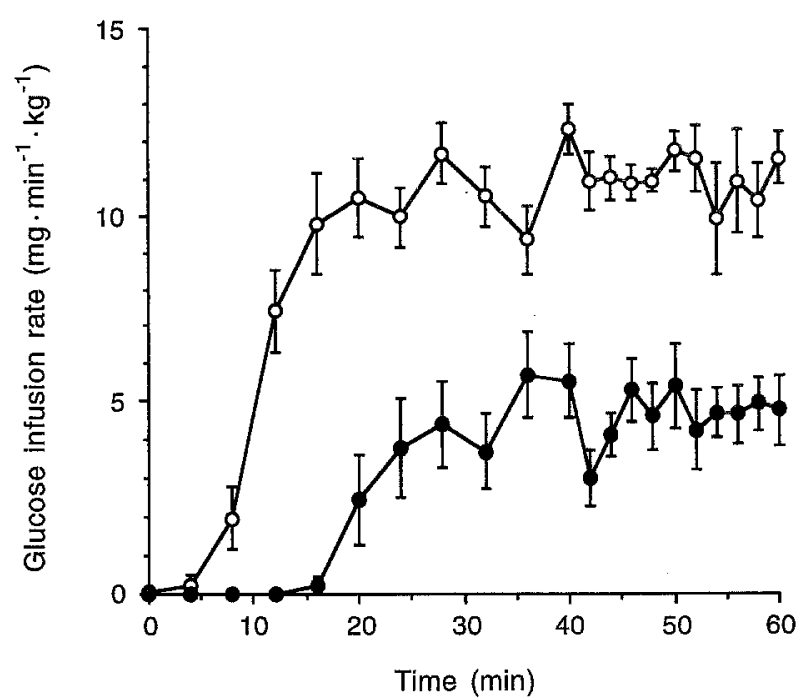

Fig. 2 (A, B). Blood glucose concentrations (A) and glucose infusion rates (B) during euglycaemic clamp experiments. Data shown for 30-week-old rats. Values shown for LETO $(0)$ and OLETF $(\bullet)$ rats. Mean \pm SEM. $(n=9)$

LETO rats. Thus, although OLETF rats exhibited insulin resistance in the skeletal muscle in vivo and in vitro, the above results demonstrated that there were no marked defects in the insulin receptor functions.

\section{Discussion}

Recent studies have suggested that the accumulation of intra-abdominal visceral fat causes insulin resistance in humans [3-5]. In OLETF rats, intra-abdominal visceral fat significantly accumulated from 12 weeks old compared with LETO rats (Fig. 1). Shima et al. [22] reported that exercise training using a wheel cage decreased the accumulation of intra-abdominal visceral fat in OLETF rats, resulting in an

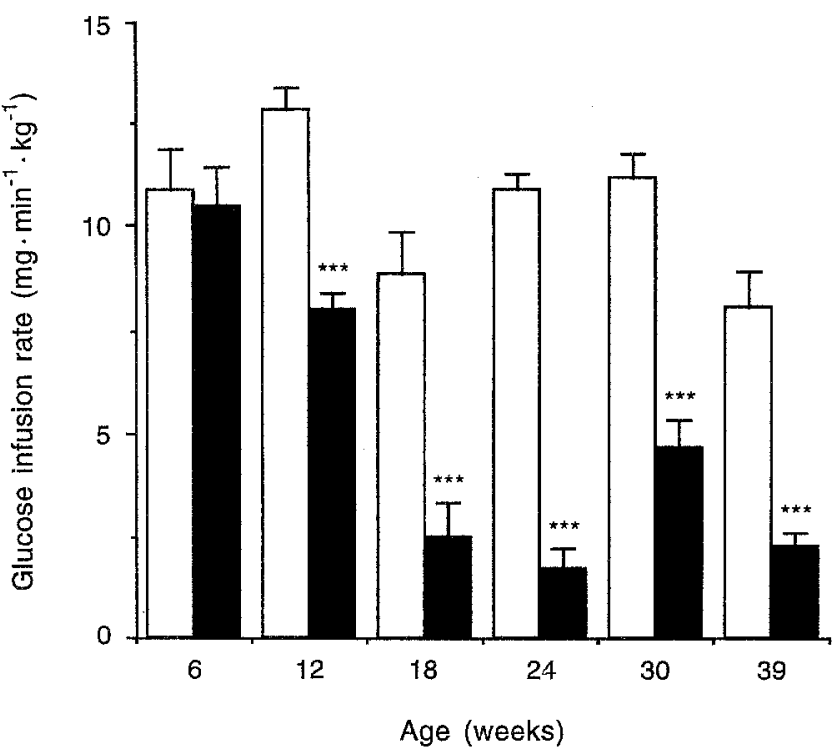

Fig.3. Comparison of glucose infusion rates of LETO and OLETF rats. The glucose infusion rate was assessed as the mean value from 40 to $60 \mathrm{~min}$ during euglycaemic hyperinsulinaemic clamp experiments. Values shown for LETO ( $\square$ ) and OLETF ( ) rats. Mean \pm SEM, $* * * p<0.001$ vs age-matched LETO rats $(n=5-10)$
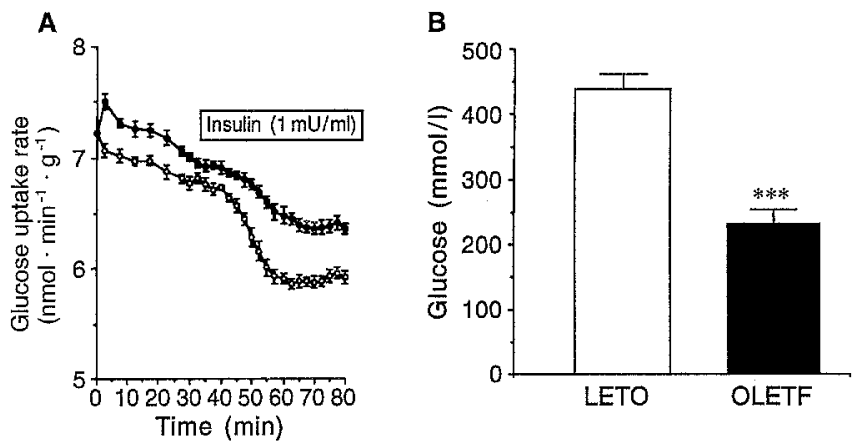

Fig. 4(A, B). Insulin-stimulated glucose uptake in hindlimb perfused preparations. The right hindlimb was perfused with Krebs solution containing $7.2 \mathrm{mmol} / 1$ glucose, $3.5 \%$ dextran T70 and $0.5 \% \mathrm{BSA}$ at $10 \mathrm{ml} / \mathrm{min}$. After $40 \mathrm{~min}$ of equilibrium, $1 \mathrm{mU} / \mathrm{ml}$ of insulin was infused for $40 \mathrm{~min}$. A Glucose concentration of the hindlimb perfusion in LETO $(0)$ and OLETF ( ) rats. B Insulin-stimulated glucose uptake by the hindlimb of LETO $(\square)$ and OLETF ( $)$ rats. Mean \pm SEM, **** $p<0.001$ vs age-matched LETO rats $(n=6$ and 7 , in LETO and OLETF rats, 40 weeks old, respectively)

improvement of their insulin resistance. These findings suggest a positive correlation between the accumulation of intra-abdominal visceral fat and insulin resistance in OLETF rats, a valuable relationship that is unique among fatty and NIDDM model rats. Björntorp [5] proposed that the visceral fat accumulation in the portal area might cause hepatic insulin resistance. In OLETF rats, the predominant increase in visceral fat was observed in the retroperitoneal area, which is supposed to be unrelated to the portal area. Further study is needed to clarify whether or 


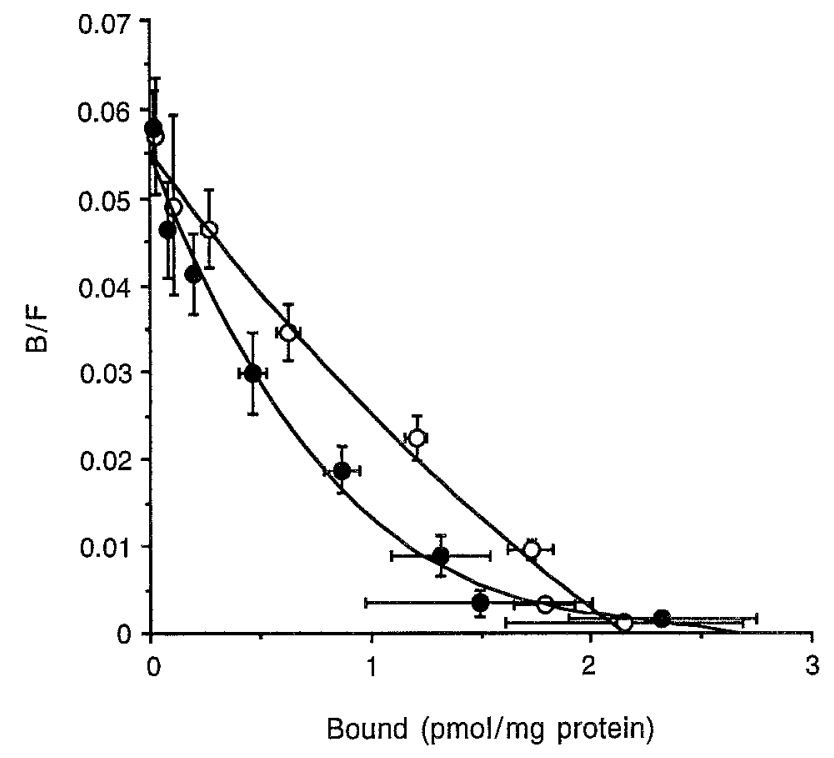

Fig.5. Scatchard plots of insulin binding to skeltal muscle insulin receptor. Binding experiment was carried out as described in Methods. The $B_{\max }$ and $K_{d}$ were determined $\left(B_{\max }=\right.$ $1.72 \pm 0.09$ and $1.66 \pm 0.03 \mathrm{pmol} / \mathrm{mg}$ protein, $K_{d}=1.91 \pm 0.18$ and $1.83 \pm 0.34 \mathrm{nmol} / \mathrm{l}$ in LETO (O) and OLETF (•) rats, respectively). Mean $\pm \operatorname{SEM}(n=3,28$ weeks old, 2 experiments each)

not the accumulation of retroperitoneal fat is related to the prevalence of insulin resistance.

We also examined the existence of insulin resistance in OLETF rats by euglycaemic hyperinsulinaemic clamp experiments in vivo. In these experiments, the glucose infusion rate in OLETF rats was found to be about $25 \sim 60 \%$ of that in LETO rats from 12 weeks old, indicating the development of insulin resistance in the whole body of OLETF rats (Fig.3). The plasma insulin concentrations after clamp experiments were higher in OLETF rats, although the same amount of exogenous insulin was infused. This might be the result of decreased insulin clearance in OLETF rats. It is interesting that the extent of hypertriglyceridaemia was inversely proportional to the glucose infusion rate (Table 1). It has been reported that the suppression of hepatic glucose production (output) by insulin is more sensitive than the stimulation of glucose uptake by insulin in peripheral tissues $[23,24]$. Thus, hepatic glucose output would be inhibited during these hyperinsulinaemic clamp experiments, although further experiments using a tracer are required to give conclusive evidence regarding the existence of hepatic insulin resistance in OLETF rats. The hindlimb perfusion experiments showed that insulin-stimulated glucose uptake in OLETF rats was $55 \%$ of that of LETO rats, indicating that at least the skeletal muscle itself of OLETF rats is insulin resistant. We conducted a $48-\mathrm{h}$ fast because it had been described in a previous paper on hindlimb perfusion [16]. The extent of insulin resistance in clamp and hindlimb perfusion cannot
A

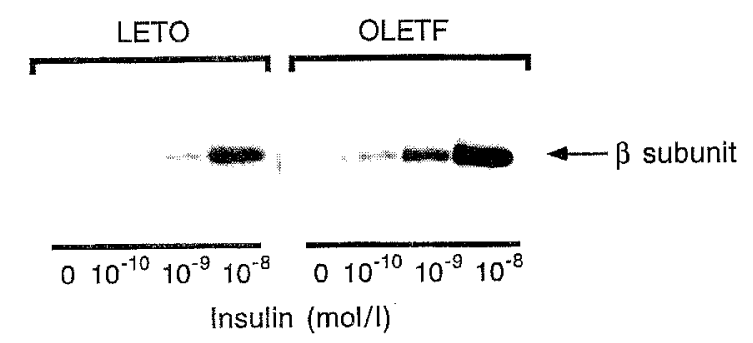

B

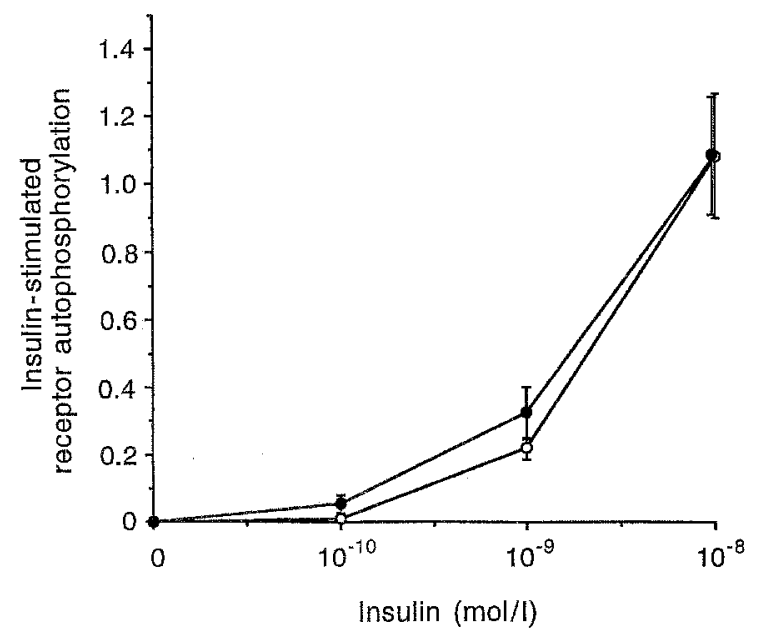

Fig.6(A, B). Analysis of insulin receptor autophosphorylation. A Partially purified insulin receptor (up to $25 \mu \mathrm{l}$ up to $7 \mu \mathrm{g}$ of glycoprotein) was incubated with various concentrations $\left(0 \sim 10^{-8} \mathrm{~mol} / \mathrm{l}\right)$ of insulin and subjected to $7.5 \%$ gel SDS-PAGE and Western blotting. Autophosphorylation of the $\beta$ subunit was detected by ECL with anti-phosphotyrosine antibody. Representative data are shown. B Autophosphorylation without insulin was subtracted from each value and the net autophosphorylation by exogenous insulin is shown. Densitometric values shown for autophosphorylation of receptors purified from LETO $(O)$ and OLETF $(\bullet)$ rats. Mean \pm SEM $(n=5,30$ weeks old $)$

be directly compared because the fasting condition and the dose of exogenous insulin were different. However, it is plausible that this insulin resistance in the skeletal muscle might cause the reduced glucose infusion rate in vivo.

It has been reported that the receptor autophosphorylation and insulin-stimulated tyrosine kinase activity of the skeletal muscle in human patients with NIDDM were lower than those of control subjects [12-15]. However, the kinase activity was at a normal level when the patients lost body weight, suggesting that this decrease in activity might be a secondary effect [25]. In genetically insulin resistant ob/ $\mathrm{ob}$ and $\mathrm{db} / \mathrm{db}$ mice, it has been reported that the insulin receptor tyrosine kinase activity of the skeletal muscle is no different from that of lean controls [26]. Wistar fatty rats and obese Zucker rats show lower tyrosine kinase activity than lean controls [27, 28]. 
A

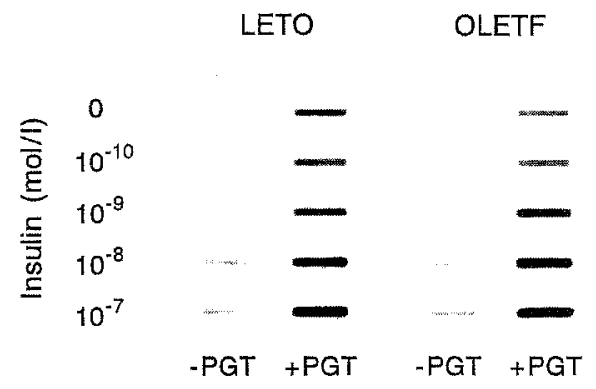

B

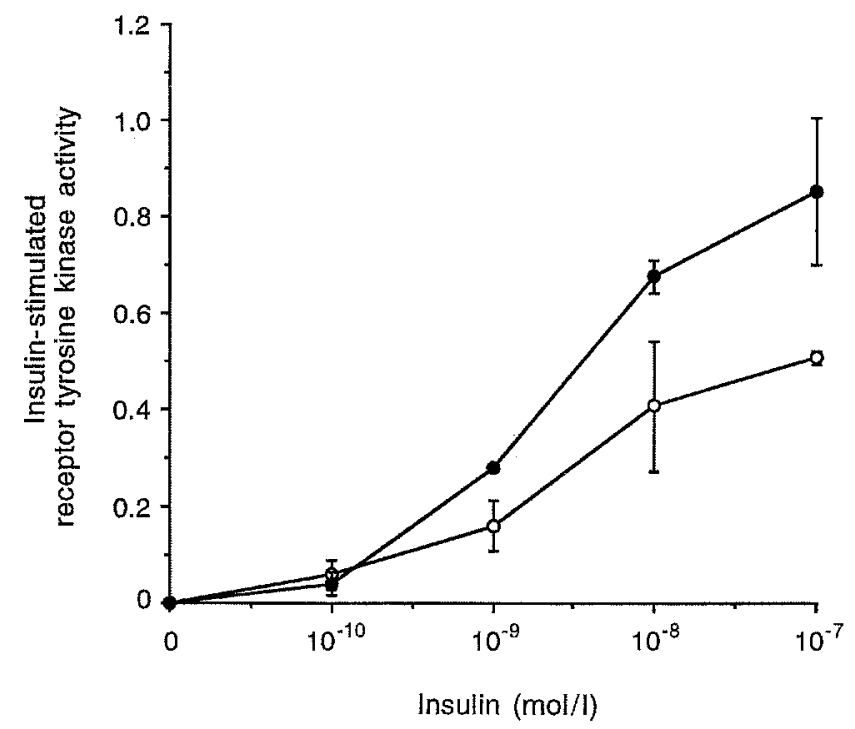

Fig.7(A, B). Analysis of insulin receptor tyrosine kinase activity. A Partially purified insulin receptor (up to $25 \mu \mathrm{l}$, up to $7 \mu \mathrm{g}$ of glycoprotein) was incubated with various concentrations $\left(0 \sim 10^{-7} \mathrm{~mol} / \mathrm{l}\right)$ of insulin following incubation with or without synthetic substrate $(2 \mathrm{mg} / \mathrm{ml})$. The reaction mixture was then subjected to slot-blot analysis, and tyrosine kinase activity was detected by ECL with anti-phosphotyrosine antibody. Representative data are shown. B The kinase activity without insulin was subtracted from each value and the net activity by exogenous insulin is shown. Densitometric values shown for tyrosine kinase activity of receptors purified from LETO $(0)$ and OLETF $(\bullet)$ rats. Mean \pm SEM $(n=3$, 30 weeks old, two experiments each)

Based on these background findings, we partially purified the insulin receptor from the skeletal muscle and investigated its functions. In insulin-binding experiments there were no marked differences in $K_{d}$ or $\mathbf{B}_{\max }$ between LETO and OLETF rats. Nor do we know whether or not the glycoprotein content which was bound to the wheat germ agglutinin column in the skeletal muscle was the same in the two strains. The insulin-stimulated autophosphorylation of the receptor was not significantly different between LETO and OLETF rats (Fig. 6). This is the first report to apply the ECL detection method in a comparison of insulin receptor autophosphorylation. The densitometric value of basal autophosphorylation was greater in OLETF than LETO rats, and this might be due to a high plasma insulin concentration in OLETF rats. Figure 7B shows the graph slightly shifting to the right in the case of LETO rats. This right-shifting might also be due to a higher plasma insulin concentration in OLETF than LETO rats, because the higher basal autophosphorylation was described in the case of OLETF rats. On the other hand, our results cannot exclude the possibility that the insulin receptor functions of OLETF skeletal muscle are decreased in the in vivo condition.

Randle et al. [29] proposed a glucose-fatty acid cycle in which a vicious metabolic circle occurs as a consequence of the inhibition of insulin-stimulated glucose utilization by dominant fatty acid utilization in the case of starvation or diabetes mellitus. OLETF rats show the development of marked hypertriglyceridaemia concomitant with body weight gain, and also the development of insulin resistance (Table 1 and Fig. 3). It has been reported that non-esterified fatty acid decreases the binding, action and degradation of insulin in hepatocytes [30, 31]. Thus, we assume that innate over-eating in male OLETF rats leads to body weight gain, especially through intraabdominal visceral fat accumulation, which causes hyperlipidaemia and insulin resistance.

Human NIDDM has increased several-fold in modern society in the past few decades. The study of the pathogenetic mechanisms of NIDDM in OLETF rats might give some clue for understanding the pathogenetic mechanism of the disease in humans.

Acknowledgements. We thank Dr. T. Kadowaki (Third Department of Internal Medicine, Faculty of Medicine, University of Tokyo) for the gift of anti-insulin receptor antibody. We also thank Dr. K. Shima (Departments of Laboratory Medicine and Pathology, School of Medicine, University of Tokushima) and Dr. M.Iwanishi (First Department of Internal Medicine, Toyama Medical and Pharmaceutical University) for their useful observations.

\section{References}

1. Kawano K, Hirashima T, Mori S, Kurosumi M, Saitoh Y (1991) A new rat strain with non-insulin dependent diabetes mellitus, "OLETF". Rat News Lett 25: 24-26

2. Kawano K, Hirashima T, Mori S, Saitoh Y, Kurosumi M, Natori T (1992) Spontaneous long-term hyperglycemic rat with diabetic complications: Otsuka Long-Evans Tokushima Fatty (OLETF) strain. Diabetes 41: 1422-1428

3. Fujioka S, Matsuzawa Y, Tokunaga K, Tarui S (1987) Contribution of intra-abdominal fat accumulation to the impairment of glucose and lipid metabolism in human obesity. Metabolism 36: 54-59

4. Fujioka S, Matsuzawa Y, Tokunaga K et al. (1991) Improvement of glucsoe and lipid metabolism associated with selective reduction of intra-abdominal visceral fat in premenopausal women with visceral fat obesity. Int $\mathbf{J}$ Obes 15: 853-859 
5. Björntorp P (1991) Metabolic implications of body fat distribution. Diabetes Care 14: 1132-1143

6. Kahn CR, White MF (1988) The insulin receptor and the molecular mechanism of insulin action. J Clin Invest 82: 1151-1156

7. Kasuga M, Karlsson FA, Kahn CR (1982) Insulin stimulates the phosphorylation of the 95,000 -dalton subunit of its own receptor. Science 215: 185-187

8. Rosen OM (1987) After insulin binds. Science 237: 14521458

9. Morgan DO, Ho L, Korn LJ, Roth RA (1986) Insulin action is blocked by a monoclonal antibody that inhibits the insulin receptor kinase. Proc Natl Acad Sci USA 83: 328-332

10. Ellis L, Clauser E, Morgan DO, Edery M, Roth RA, Rutter WJ (1986) Replacement of insulin receptor tyrosine residues 1162 and 1163 compromises insulin-stimulated kinase activity and uptake of 2-deoxyglucose. Cell 45: 721-732

11. Chou CK, Dull TJ, Russell DS et al. (1987) Human insulin receptors mutated at the ATP-binding site lack protein tyrosine kinase activity and fail to mediate postreceptor effects of insulin. J Biol Chem 262: 1842-1847

12. Obermaier-Kusser B, White MF, Pongratz DE et al. (1989) A defective intramolecular autoactivation cascade may cause the reduced kinase activity of the skeletal muscle insulin receptor from patients with non-insulin-dependent diabetes mellitus. J Biol Chem 264: 9497-9504

13. Arner P, Pollare T, Lithell H, Livingston JN (1987) Defective insulin receptor tyrosine kinase in human skeletal muscle in obesity and type 2 (non-insulin-dependent) diabetes mellitus. Diabetologia 30: 437-440

14. Caro JF, Sinha MK, Raju SM et al. (1987) Insulin receptor kinase in human skeletal muscle from obese subjects with and without noninsulin dependent diabetes. J Clin Invest 79: $1330-1337$

15. Nyomba BL, Ossowski VM, Bogardus C, Mott DM (1990) Insulin-sensitive tyrosine kinase: relationship with in vivo insulin action in humans. Am J Physiol 258: E964-E967

16. Ruderman NB, Houghton CRS, Hems R (1971) Evaluation of the isolated perfused rat hindquarter for the study of muscle metabolism. Biochem J 124: 639-651

17. Burant CF, Treutelaar MK, Landreth GE, Buse MG (1984) Phosphorylation of insulin receptors solubilized from rat skeletal muscle. Diabetes 33: 704-708

18. Freidenberg GR, Suter SL, Henry RR, Reichart D, Olefsky JM (1991) In vivo stimulation of the insulin receptor kinase in human skeletal muscle. J Clin Invest 87: 2222-2229
19. Bradford MM (1976) A rapid and sensitive method for quantitation of microgram quantities of protein utilizing the principal of protein-binding. Anal Biochem 72: 248-254

20. Burant CF, Treutelaar MK, Buse MG (1986) Diabetes-induced functional and structural changes in insulin receptors from rat skeletal muscle. J Clin Invest 77: 260-270

21. Rijksen G, van Oirschot BA, Staal GEJ (1991) Nonradioactive assays of protein tyrosine kinase activity using antiphosphotyrosine antibodies. Methods Enzymol 200: 98-107

22. Shima K, Shi K, Sano T, Iwami T, Mizuno A, Noma Y (1993) Is exercise training effective in preventing diabetes mellitus in the Otsuka-Long-Evans-Tokushima Fatty rat, a model of spontaneous non-insulin-dependent diabetes mellitus? Metabolism 42: 971-977

23. Olefsky JM, Kolterman OG, Scarlett JA (1982) Insulin action and resistance in obesity and noninsulin-dependent type II diabetes mellitus. Am J Physiol 243: E15-E30

24. Ishida T, Chap Z, Chou J et al. (1984) Effects of portal and peripheral venous insulin infusion on glucose production and utilization in depancreatized, conscious dogs. Diabetes 33: 984-990

25. Friedman JE, Dohm GL, Leggett-Frazier N et al. (1992) Restoration of insulin responsiveness in skeletal muscle of morbidly obese patients after weight loss. J Clin Invest 89 : 701-705

26. Vicario P, Brady EJ, Slater EE, Saperstein R (1987) Insulin receptor tyrosine kinase activity is unaltered in $\mathrm{ob} / \mathrm{ob}$ and $\mathrm{db} / \mathrm{db}$ mouse skeletal muscle membranes. Life Sci 41: 1233-1241

27. Kobayashi M, Iwanishi M, Egawa K, Shigeta Y (1992) Pioglitazone increases insulin sensitivity by activating insulin receptor kinase. Diabetes 41: 476-483

28. Slieker LJ, Roberts EF, Shaw WN, Johnson WT (1990) Effect of streptozocin-induced diabetes on insulin-receptor tyrosine kinase activity in obese Zucker rats. Diabetes 39: 619-625

29. Randle PJ, Garland PB, Hales CN, Newsholme EA (1963) The glucose fatty-acid cycle. Its role in insulin sensitivity and the metabolic disturbances of diabetes mellitus. Lancet I: $785-789$

30. Svedberg J, Björntorp P, Smith U, Lönnroth P (1990) Freefatty acid inhibition of insulin binding, degradation, and action in isolated rat hepatocytes. Diabetes 39: 570-574

31. Hennes MMI, Shrago E, Kissebah AH (1990) Receptor and postreceptor effects of free fatty acids (FFA) on hepatocyte insulin dynamics. Int J Obes 14: 831-841 